\title{
Modelling and Simulation for Small Signal Stability of Multi-machine Power System under Various Disturbance Conditions
}

\author{
Ohnmar Swe \\ Department of Electrical Power \\ Engineering \\ Yangon Technological University \\ Yangon, Myanmar \\ ohnmarswe1996@gmail.com
}

\author{
Soe Win \\ Department of Electrical Power \\ Engineering \\ Yangon Technological University \\ Yangon, Myanmar \\ soewin1982@gmail.com
}

\author{
Zarchi linn \\ Department of Electrical Power \\ Engineering \\ Yangon Technological University \\ Yangon, Myanmar \\ zclinn@gmail.com
}

\begin{abstract}
This paper presents the small signal stability of multi-machine power system over the 58-Bus, 26-Machine, Yangon Distribution Network and is validated with MATLAB software under various disturbance conditions. Time-domain solution analysis is employed to determine the small signal dynamic behavior of test system. Transtability model is used to perform time-domain simulation in SIMULINK. The simulation is carried out for normal condition, reference voltage of regulator $\left(V_{\text {ref }}\right)$ disturbance, mechanical torque $\left(T_{m}\right)$ disturbance and network (fault) disturbance and the conditions of change in center of inertia for rotor angle (delta COI), slip for center of inertia (slip COI), field current and mechanical torque are observed. According to the simulation results, perturbation of $V_{\text {ref }}$ shows only instability on the system. But ramping of $T_{m}$ and network disturbance can cause large disturbance on the system and unstable conditions can be observed.
\end{abstract}

Keywords - load flow, small signal stability analysis, timedomain simulation, multi-machine power system, system disturbances

\section{INTRODUCTION}

Increased requirement of electric power together with the restraints to build new transmission lines causes the transmission systems to operate touching the stability limits. To meet the demand, such stressed power system requires advance monitoring and control system to detect and respond to any disturbances immediately so that stability can be preserved. Stability study is divided in two parts, transient stability and steady state or small signal stability. Transient stability is concerned with large external disturbances such as fault on transmission line. Small signal stability is concerned with the rotor angle or speed deviation of generators which varies due to random load variations [1].

Small-signal rotor angle stability analysis mainly deals with a study of electromechanical oscillations-related performance of the system about an operating point when the system is subjected to sufficiently small magnitude of disturbance that will not trigger non-linear behavior of the system. Thus, this study is mainly concerned with the ability of the power system to maintain synchronism under small disturbances. The disturbances are considered to be sufficiently small that linearization of system equations is possible for analysis purposes. This permits linear system theory to be applied for system analysis even though the system is inherently non-linear [2].

If the power system at a given operating condition may be large disturbance unstable, still such a system can be operated, though unsecurely. However, if the system is small-signal unstable at a given operating condition, it cannot be operated. Therefore, small signal stability is a fundamental requirement for the satisfactory operation of power systems [3].

When a dynamic system such as power system is perturbed from its steady state condition, the system variables trace out a flow, referred to as trajectories. These trajectories may exhibit oscillatory or monotonic behavior. For the system to be stable, these trajectories must remain bounded and converge to an acceptable operating point.

In this paper a realistic multi-machine power system has been taken as a test case and simulation is conducted considering full-order linearized model including all type of network buses.

\section{Modelling For SMall Signal Stability Study OF POWER SYSTEM}

\section{A. Load Flow Studies}

Load flow analysis provides the initial operating values for the system variables, before any dynamic analysis is carried out. Thus, it avoids long duration time-domain simulation to arrive at a pre-fault operating condition. Load flow problem generally involves the simultaneous solution of many non-linear algebraic equations using numerical iterative procedure. Most commonly used iterative methods are the Gauss-Seidel, the Newton-Raphson (NR) and fast decouple load flow (FDLF) methods. In this study, FDLF method is employed for the load flow solution [4].

\section{B. Generator Model}

A 3 phase synchronous machine is modelled in the rotor reference frame as shown in Fig. 1. The figure also depicts two rotor windings, including the field winding ' $\mathrm{f}$ ' along $\mathrm{d}$ axis and two rotor coils along q-axis. The short circuited coils, one along d-axis (' $h$ ') and two along q-axis (' $g$ ' and ' $k$ ') represent the effect of damper windings and eddy currents induced in the rotor mass [5]. 
JAREE-Journal on Advance Research in Electrical Engineering Volume4, Number 1, April 2020

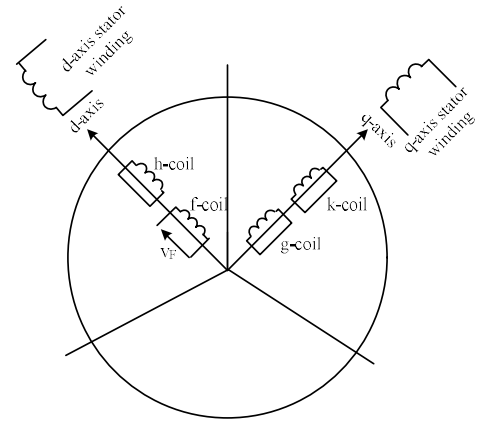

Fig. 1. Synchronous Machine Model

1) Rotor Equations:

The differential equations are written in the state-space form as follows:

$$
\begin{aligned}
& \frac{\mathrm{d} \psi_{\mathrm{f}}}{\mathrm{dt}}=\frac{1}{\mathrm{~T}_{\mathrm{d}}^{\prime}}\left[-\psi_{\mathrm{f}}+\psi_{\mathrm{d}}+\left(\frac{\mathrm{x}_{\mathrm{d}}^{\prime}}{\mathrm{x}_{\mathrm{d}}-\mathrm{x}_{\mathrm{d}}^{\prime}}\right) \mathrm{E}_{\mathrm{fd}}\right] \\
& \frac{\mathrm{d} \psi_{\mathrm{h}}}{\mathrm{dt}}=\frac{1}{\mathrm{~T}_{\mathrm{d}}^{\prime \prime}}\left[-\psi_{\mathrm{h}}+\psi_{\mathrm{d}}\right] \\
& \frac{\mathrm{d} \psi_{\mathrm{g}}}{\mathrm{dt}}=\frac{1}{\mathrm{~T}_{\mathrm{q}}^{\prime}}\left[-\psi_{\mathrm{g}}+\psi_{\mathrm{q}}\right] \\
& \frac{\mathrm{d} \psi_{\mathrm{k}}}{\mathrm{dt}}=\frac{1}{\mathrm{~T}_{\mathrm{q}}^{\prime \prime}}\left[-\psi_{\mathrm{k}}+\psi_{\mathrm{q}}\right]
\end{aligned}
$$

2) Stator Equations:

Neglecting stator transients and ignoring speed variations, the stator $\mathrm{d}-$ and $\mathrm{q}$-axes voltage equations are given by,

$$
\begin{aligned}
& \mathrm{v}_{\mathrm{d}}=-\mathrm{i}_{\mathrm{d}} \mathrm{R}_{\mathrm{a}}-\psi_{\mathrm{q}} \\
& \mathrm{v}_{\mathrm{q}}=-\mathrm{i}_{\mathrm{q}} \mathrm{R}_{\mathrm{a}}+\psi_{\mathrm{d}}
\end{aligned}
$$

3) Swing Equations:

The rotor mechanical equations are given by,

$$
\begin{aligned}
& \frac{\mathrm{d} \delta}{\mathrm{dt}}=\mathrm{S}_{\mathrm{m}} \omega_{\mathrm{B}} \\
& \frac{\mathrm{dS} \mathrm{m}_{\mathrm{m}}}{\mathrm{dt}}=\frac{1}{2 \mathrm{H}}\left[\mathrm{T}_{\mathrm{m}}-\mathrm{T}_{\mathrm{e}}-\mathrm{DS}_{\mathrm{m}}\right]
\end{aligned}
$$

$\mathrm{S}_{\mathrm{m}}=$ per unit slip

$\omega_{\mathrm{B}}=$ base speed in $\mathrm{rad} / \mathrm{s}$

$\mathrm{H}=$ inertia constant of a generator in per unit

$\mathrm{T}_{\mathrm{m}}=$ mechanical input torque in per unit

$\mathrm{D}=$ mechanical damping in per unit

The electromagnetic torque can be written as

$$
\mathrm{T}_{\mathrm{e}}=\mathrm{E}_{\mathrm{q}}^{\prime \prime} \mathrm{i}_{\mathrm{q}}+\mathrm{E}_{\mathrm{d}}^{\prime \prime} \mathrm{i}_{\mathrm{d}}+\left(\mathrm{x}_{\mathrm{d}}^{\prime \prime}-\mathrm{x}_{\mathrm{q}}^{\prime \prime}\right) \mathrm{i}_{\mathrm{d}} \mathrm{i}_{\mathrm{q}}
$$

\section{4) Centre of Inertia Reference}

The distance to center of inertia (COI) in terms of rotor angles and rotor speed deviations are defined as follows:

$$
\begin{aligned}
& \delta_{\mathrm{COI}}=\frac{1}{\mathrm{H}_{\mathrm{T}}} \sum_{\mathrm{i}=1}^{\mathrm{n}_{\mathrm{g}}} \mathrm{H}_{\mathrm{i}} \delta_{\mathrm{i}} \\
& \omega_{\mathrm{COI}}=\frac{1}{\mathrm{H}_{\mathrm{T}}} \sum_{\mathrm{i}=1}^{\mathrm{n}_{\mathrm{g}}} \mathrm{H}_{\mathrm{i}} \omega_{\mathrm{i}} \\
& \overline{\delta_{\mathrm{i}}}=\delta_{\mathrm{i}}-\delta_{\mathrm{COI}} \\
& \overline{\omega_{\mathrm{i}}}=\omega_{\mathrm{i}}-\omega_{\mathrm{COI}}
\end{aligned}
$$

In the time-domain simulation, the stability of a system is inferred by plotting $\overline{\delta_{i}}$ against time [6].

\section{IEEE-Type AC4A Exciter Model}

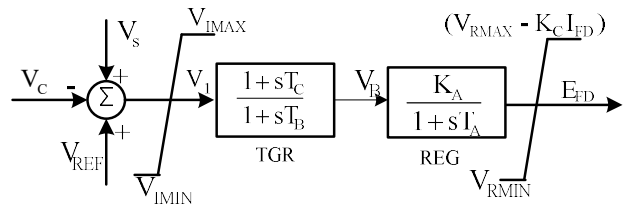

Fig. 2. IEEE-type AC4A excitation system Source: [5]

IEEE-Type AC4A excitation system is given in fig. 2 . Its differential equations are as follows:

$$
\begin{aligned}
\frac{\mathrm{dx}_{\mathrm{B}}}{\mathrm{dt}} & =\frac{1}{\mathrm{~T}_{\mathrm{B}}}\left[-\mathrm{x}_{\mathrm{B}}+\left(1-\frac{\mathrm{T}_{\mathrm{C}}}{\mathrm{T}_{\mathrm{B}}}\right)\left(\mathrm{V}_{\mathrm{ref}}+\mathrm{V}_{\mathrm{s}}-\mathrm{V}_{\mathrm{c}}\right)\right] \\
\frac{\mathrm{dE}_{\mathrm{fd}}}{\mathrm{dt}} & =\frac{1}{\mathrm{~T}_{\mathrm{A}}}\left[-\mathrm{E}_{\mathrm{fd}}+\mathrm{K}_{\mathrm{A}}\left(\mathrm{x}_{\mathrm{B}}+\frac{\mathrm{T}_{\mathrm{C}}}{\mathrm{T}_{\mathrm{B}}}\left(\mathrm{V}_{\mathrm{ref}}+\mathrm{V}_{\mathrm{s}}-\mathrm{V}_{\mathrm{c}}\right)\right)\right]
\end{aligned}
$$

$\mathrm{V}_{\mathrm{c}}=$ output of the voltage tranducer

$\mathrm{V}_{\mathrm{s}}=$ output of the power system stabilizer

$\mathrm{V}_{\text {ref }}=$ voltage regulator reference

$\mathrm{T}_{\mathrm{A}}=$ time constant associated with the regulator and firing of thyristors

$\mathrm{K}_{\mathrm{A}}=$ overall gain

D. Hydro Turbine and its Speed Governor Model

The hydro turbine and its speed governor model are shown in fig. 3.

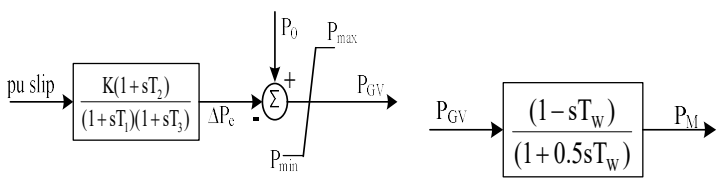

(a) Speed governor model

(b) Hydro turbine model

Fig. 3. Hydro turbine and its Speed Governor model Source: [5]

Its differential equations are given by,

$$
\begin{aligned}
& \frac{\mathrm{dy}_{1}}{\mathrm{dt}}=\frac{1}{\mathrm{~T}_{1}}\left[\mathrm{~K}\left(1-\frac{\mathrm{T}_{2}}{\mathrm{~T}_{1}}\right) \mathrm{S}_{\mathrm{m}}-\mathrm{y}_{1}\right] \\
& \frac{\mathrm{dP}_{\mathrm{GV}}}{\mathrm{dt}}=\frac{1}{\mathrm{~T}_{3}}\left[-\mathrm{K} \frac{\mathrm{T}_{2}}{\mathrm{~T}_{1}} \mathrm{~S}_{\mathrm{m}}-\mathrm{y}_{1}-\mathrm{P}_{\mathrm{GV}}\right] \\
& \frac{\mathrm{dz}_{1}}{\mathrm{dt}}=\frac{2}{\mathrm{~T}_{\mathrm{W}}}\left[3 \mathrm{P}_{\mathrm{GV}}-\mathrm{z}_{1}\right]
\end{aligned}
$$

$\mathrm{T}_{\mathrm{w}}=$ water starting time

$\mathrm{P}_{\mathrm{GV}}=$ output of the governor

\section{E. Speed Governor Model for Steam Turbine}

The speed governor model for steam turbine is given in fig. 4.

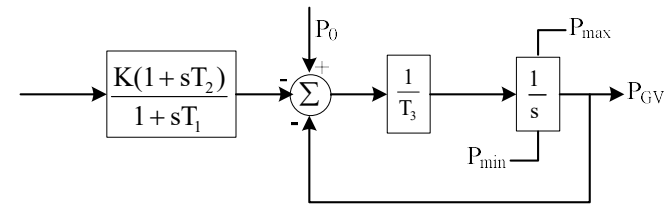

Fig. 4. Speed governor model for steam turbine Source: [5]

The steam turbine has the two major types. They are

1. Tandem Compounded, Single Reheat Type

2. Non-Reheat Type

1) Tandem Compounded, Single Reheat Type

The reheat type of steam turbine model is shown in fig. 5. The differential equations for the reheat type steam turbine and its associated speed governor are given by,

$$
\frac{\mathrm{dx}_{1}}{\mathrm{dt}}=\frac{1}{\mathrm{~T}_{\mathrm{CH}}}\left(\mathrm{P}_{\mathrm{GV}}-\mathrm{x}_{1}\right)
$$


JAREE-Journal on Advance Research in Electrical Engineering Volume4, Number 1, April 2020

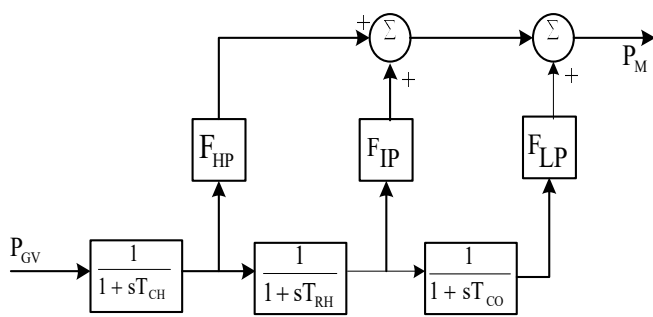

Fig. 5. Tandem compounded, single-reheat-type steam turbine model Source: [6]

$$
\begin{aligned}
\frac{\mathrm{dx}_{2}}{\mathrm{dt}} & =\frac{1}{\mathrm{~T}_{\mathrm{RH}}}\left(\mathrm{x}_{1}-\mathrm{x}_{2}\right) \\
\frac{\mathrm{dx}_{3}}{\mathrm{dt}} & =\frac{1}{\mathrm{~T}_{\mathrm{CO}}}\left(\mathrm{x}_{2}-\mathrm{x}_{3}\right) \\
\frac{\mathrm{dy}_{1}}{\mathrm{dt}} & =\frac{1}{\mathrm{~T}_{1}}\left[\mathrm{~K}\left(1-\frac{\mathrm{T}_{2}}{\mathrm{~T}_{1}}\right) \mathrm{S}_{\mathrm{m}}-\mathrm{y}_{1}\right] \\
\frac{\mathrm{dP}}{\mathrm{dt}} & =\frac{1}{\mathrm{~T}_{3}}\left[\mathrm{P}_{0}-\mathrm{K} \frac{\mathrm{T}_{2}}{\mathrm{~T}_{1}} \mathrm{~S}_{\mathrm{m}}-\mathrm{y}_{1}-\mathrm{P}_{\mathrm{GV}}\right]
\end{aligned}
$$

$\mathrm{T}_{\mathrm{CH}}, \mathrm{T}_{\mathrm{RH}}$ and $\mathrm{T}_{\mathrm{CO}}$ are the time constants of the steam chest, re-heater and crossover piping.

2) Non-reheat type

The non-reheat type of steam turbine model is shown in fig. 6 .

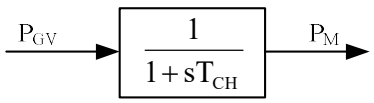

Fig. 6. Non-reheat type steam turbine model

The state variable of this type is $\mathrm{P}_{\mathrm{Gv}}$.

\section{F. Network Model}

The linearized network equation can be expressed using admittance matrix (and DQ variables) as follows:

$\left[\mathrm{Y}_{\mathrm{DQ}}\right] \Delta \mathrm{V}_{\mathrm{QD}}=\Delta \mathrm{I}_{\mathrm{DQ}}$

\section{G. Time-domain Solution Analysis}

Time-domain techniques provide an exact determination of stability of non-linear systems both for small and large disturbances. The choice of disturbance and selection of variables to be observed in time response are critical. The input, if not chosen properly, may not provide substantial excitation of the important modes. The observed response may contain many modes and the poorly damped modes may not be dominant. Number of modes depends on modeling details employed for different dynamic components. Larger systems may have a number of interarea modes of similar frequencies, and it is quite difficult to separate them from a response in which more than one is excited [7].

\section{CASE STUDY}

Case study is carried out for a 26 machine system at Yangon Distribution Network as shown in Fig. 7. This system has 58 buses, 26 lines, 37 transformers, 23 loads and 8 capacitor banks. Out of 26 lines, 10 lines are $230 \mathrm{kV}, 15$ lines are $66 \mathrm{kV}$, and the rest 1 line is $33 \mathrm{kV}$. The whole network includes 14 numbers of 3 -windings line transformers and 23 numbers of 2-windings load transformers. Bus- 1 is treated as a slack bus. All generators are provided with IEEE-type AC4A exciters. Generator 1 is with hydro-turbine, generator 22 is with reheat type steam turbine, and the rest generators are with non-reheat type steam turbines. Further, constant impedance type load model has been employed for both real and reactive components of loads.

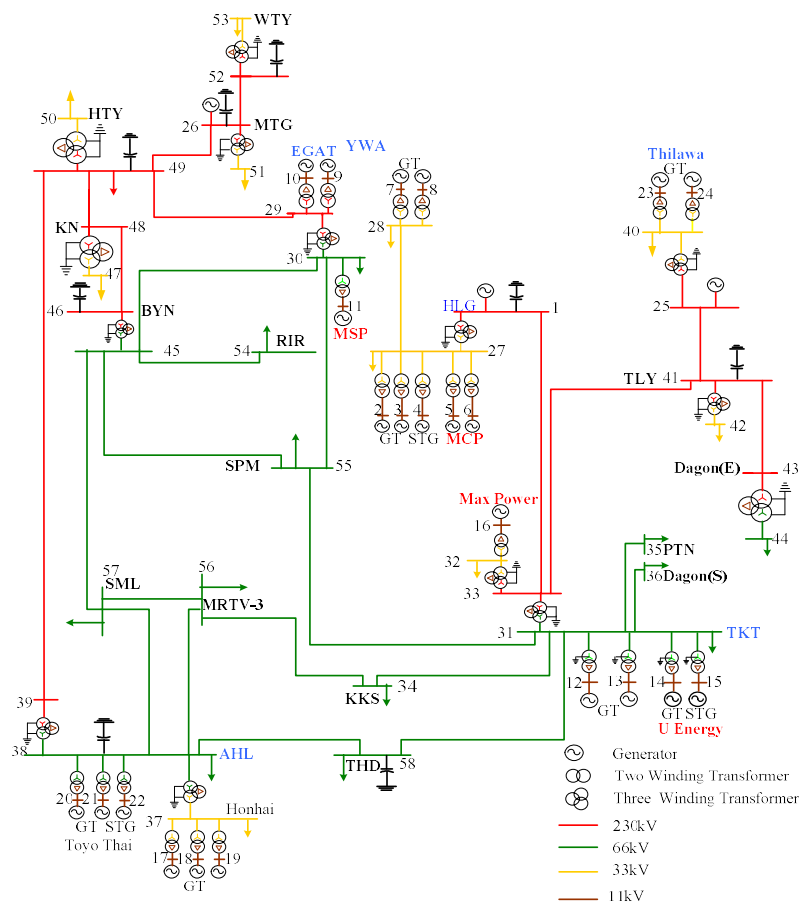

Fig. 7. Single Line Diagram for Yangon Distribution Network

The capacitor bank data and the synchronous generator data are given in Table I and Table II. All data are calculated on 100MVA base.

TABLE VII. CAPACITOR BANK DATA

\begin{tabular}{|c|c|c|}
\hline Bus No & Conductance G(pu) & Susceptance B(pu) \\
\hline 1 & 0 & 0.929 \\
\hline 26 & 0.0031 & 0.5071 \\
\hline 38 & 0.0008 & 0.4066 \\
\hline 41 & 0.06 & 1.06 \\
\hline 46 & 0 & 0 \\
\hline 49 & 0.00392 & 0.67888 \\
\hline 52 & 0 & 0.5 \\
\hline 58 & 0 & 0.16 \\
\hline
\end{tabular}

\section{SIMULATION AND RESULTS}

The Simulink model for small signal stability study is illustrated in Fig. 8. The modeling is carried out by Matlab/Simulink. For simulation of model, the matlab programs for initial condition (initcond.m), load flow program (fdlf_loadflow.m), small signal stability program (small_sig.m) and transient stability program (transtability.mdl) are formerly executed and the results are stored in workspace. For the simulation of this model, the data of 26 machines are input from Matlab workspace. The responses of each machine are recorded by using scopes. 
JAREE-Journal on Advance Research in Electrical Engineering Volume4, Number 1, April 2020

TABLE VIII. SyNCHRONOUS GENERATOR DATA

\begin{tabular}{|c|c|c|c|c|c|c|c|c|c|c|c|c|}
\hline $\begin{array}{l}\text { Machine } \\
\text { at bus }\end{array}$ & $\mathrm{x}_{\mathrm{a}}(\mathrm{pu})$ & $\begin{array}{l}\mathrm{x}_{\mathrm{i}} \\
(\mathrm{pu})\end{array}$ & 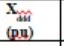 & $\begin{array}{l}\mathrm{T}_{\text {ata }} \\
\text { (puz) }\end{array}$ & $\begin{array}{l}\mathrm{T}_{\text {mut }} \\
\text { (piy) }\end{array}$ & $\mathbf{X}_{q}(\mathrm{pu})$ & $\begin{array}{l}x_{\text {甲 }} \\
\text { (pi) }\end{array}$ & 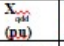 & $\begin{array}{l}\mathrm{T}_{\mathrm{pas}} \\
(\mathrm{puy})\end{array}$ & $\begin{array}{l}\mathrm{T}_{\text {an }} \\
\text { (pui) }\end{array}$ & $\mathrm{H}(\mathrm{s})$ & D \\
\hline 1 & 0.4326 & 0.1426 & 0.1226 & 4.97 & 0.04 & 0.3043 & 0.1426 & 0.1226 & 1.5 & 0.04 & 2.41 & 0 \\
\hline 2 & 3.79555 & 0.38366 & 0.24736 & 6.22 & 0.04 & 4.3598 & 0.91785 & 0.24782 & 1.5 & 0.04 & 5.34 & 0 \\
\hline 3 & 3.79555 & 0.38366 & 0.24736 & 6.22 & 0.04 & 4.3598 & 0.91785 & 0.24782 & 1.5 & 0.04 & 5.34 & 0 \\
\hline 4 & 2.80345 & 0.28191 & 0.2036 & 3.1 & 0.05 & 2.80345 & 0.28191 & 0.2036 & 1.5 & 0.05 & 6.5135 & 0 \\
\hline 5 & 8.14037 & 0.44807 & 0.3789 & 3.91 & 0.021 & 5.82486 & 5.82486 & 0.39694 & 3.471 & 3.471 & 0.83 & 0 \\
\hline 6 & 7.33333 & 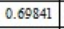 & 0.52698 & 3.91 & 0.04 & 7.33333 & 0.69841 & 0.52698 & 1.5 & 0.04 & 0.83 & 0 \\
\hline 7 & 9.24 & 0.88 & 0.664 & 5.5 & 0.04 & 0.88 & 1.14 & 0.94 & 1.5 & 0.04 & 6 & 0 \\
\hline 8 & 9.24 & 0.88 & 0.664 & 5.5 & 0.04 & 0.88 & 1.14 & 0.94 & 1.5 & 0.04 & 6 & 0 \\
\hline 9 & 1.54 & 0.14667 & 0.11067 & 7 & 0.04 & 1.33333 & 0.26667 & 0.11067 & 1.5 & 0.04 & 6.41 & 0 \\
\hline 10 & 1.54 & 0.14667 & 0.11067 & 7 & 0.04 & 1.33333 & 0.26667 & 0.11067 & 1.5 & 0.04 & 6.41 & 0 \\
\hline 11 & 2.48795 & 0.39588 & 0.27853 & 3.1 & 0.046 & 1.53361 & 1.53361 & 1.56475 & 0.6 & 0.27 & 6.5135 & 0 \\
\hline 12 & 6.8279 & 0.73124 & 0.54843 & 5 & 0.04 & 6.8279 & 0.73124 & 0.54843 & 1.5 & 0.04 & 5.06 & 0 \\
\hline 13 & 6.8279 & 0.73124 & 0.54843 & 5 & 0.04 & 6.8279 & 0.73124 & 0.54843 & 1.5 & 0.04 & 5.06 & 0 \\
\hline 14 & 2.13993 & 0.27037 & 0.17258 & 7.9 & 0.049 & 2.0594 & 0.52348 & 0.17258 & 0.51 & 0.05 & 4.5771 & 0 \\
\hline 15 & 4.0438 & 0.4988 & 0.3786 & 7 & 0.05 & 4.0438 & 0.8036 & 0.3786 & 1.5 & 0.05 & 2.264 & 0 \\
\hline 16 & 3.41292 & 0.33006 & 0.23455 & 3.7 & 0.02814 & 1.85399 & 1.85399 & 0.25843 & 0.4 & 0.29348 & 5.5901 & 0 \\
\hline 17 & 3.84228 & 0.38839 & 0.25041 & 7 & 0.04 & 3.84228 & 0.38839 & 0.25041 & 1.5 & 0.04 & 3.91 & 0 \\
\hline 18 & 3.84228 & 0.38839 & 0.25041 & 7 & 0.04 & 3.84228 & 0.38839 & 0.25041 & 1.5 & 0.04 & 3.91 & 0 \\
\hline 19 & 3.84228 & 0.38839 & 0.25041 & 7 & 0.04 & 3.84228 & 0.38839 & 0.25041 & 1.5 & 0.04 & 3.91 & 0 \\
\hline 20 & 4.33526 & 0.37062 & 0.26692 & 9.5 & 0.04 & 3.96124 & 0.44203 & 0.32302 & 2.9 & 0.04 & 5.5135 & 0 \\
\hline 21 & 4.33526 & 0.37062 & 0.26692 & 9.5 & 0.04 & 3.96124 & 0.44203 & 0.32302 & 2.9 & 0.04 & 5.5135 & 0 \\
\hline 22 & 4.87791 & 0.88469 & 0.56031 & 5.5 & 0.04 & 4.87791 & 0.49307 & 0.3179 & 1.5 & 0.04 & 0.83 & 0 \\
\hline 23 & 5.52571 & 0.69071 & 0.46048 & 11.1 & 0.05 & 2.22563 & 5.52571 & 0.63955 & 1.5 & 0.12 & 0.50766 & 0 \\
\hline 24 & 5.52577 & 0.69071 & 0.46048 & 11.1 & 0.05 & 2.22568 & 5.52571 & 0.63955 & 1.5 & 0.12 & 0.50766 & 0 \\
\hline 25 & \begin{tabular}{|l|l|}
1.54 \\
\end{tabular} & 0.14667 & 0.11067 & 7 & 0.04 & 1.33333 & 0.26667 & 0.11067 & 1.5 & 0.04 & 6.41 & 0 \\
\hline 26 & 0.4326 & 0.1426 & 0.1226 & 4.97 & 0.04 & 0.3043 & 0.1426 & 0.1226 & 1.5 & 0.04 & 2.41 & 0 \\
\hline
\end{tabular}

A time-domain simulation is carried out with four cases by using transtability programme.

Case-1: Without any disturbance

Case-2: Perturbation of $\mathrm{V}_{\text {ref }}$ for generator-1

Case-3: Ramping of $\mathrm{T}_{\mathrm{m}}$ for generator-1

Case-4: Network disturbances

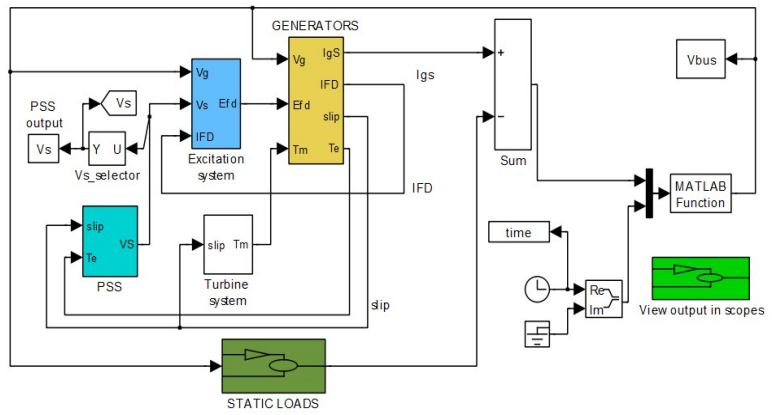

Fig. 8. Simulink Model for Small Signal Stability Study

Case-1: Without any disturbance

In this case, all machines are operated under normal condition without any disturbance. For this simulation, in program execution of small signal (small_sig.m), network disturbances, perturbation of $\mathrm{V}_{\text {ref }}$ and ramping of $\mathrm{T}_{\mathrm{m}}$ are set to zero. The important parameters for the machines are shown in Fig. 9 through Fig. 12.

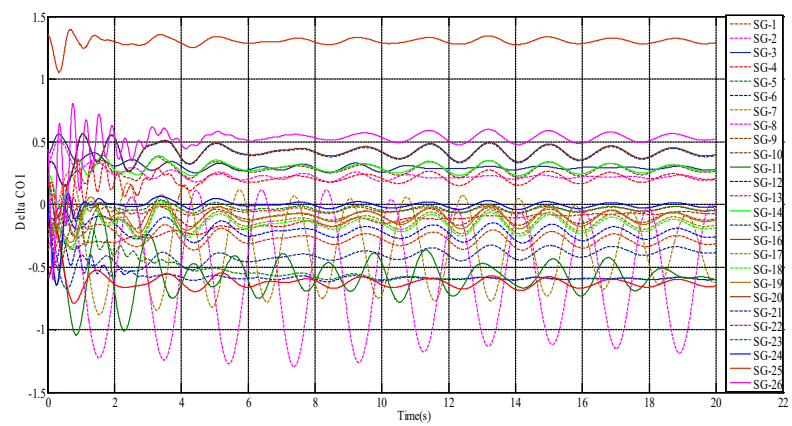

Fig. 9. Variation of rotor angles with respect to COI reference $(26 \mathrm{~m} / \mathrm{c}$ system)

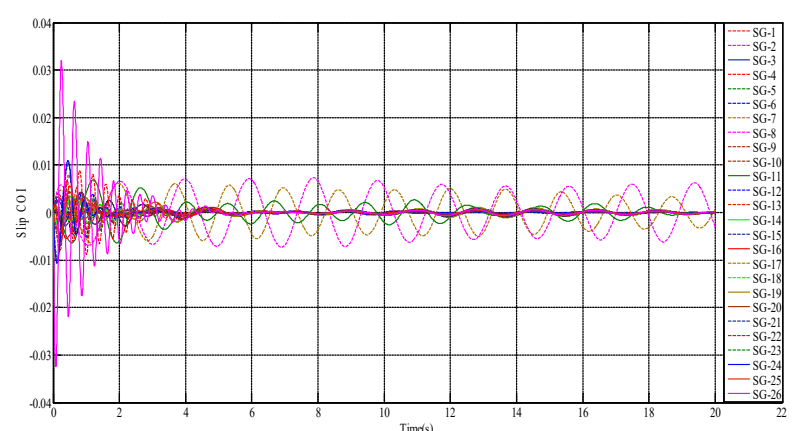

Fig. 10. Variation of slip with respect to COI reference ( $26 \mathrm{~m} / \mathrm{c}$ system)

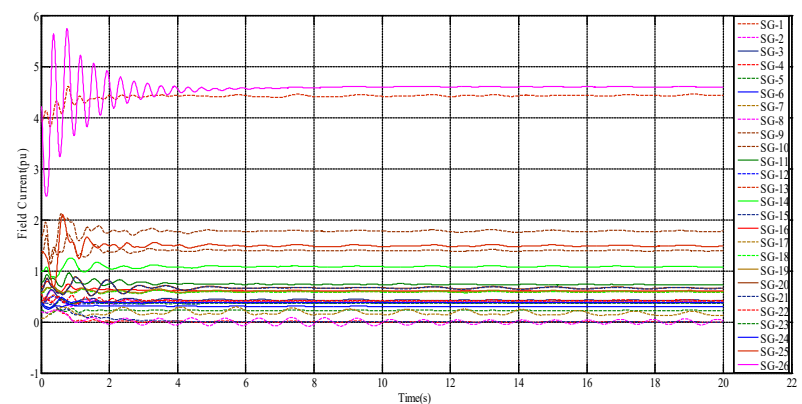

Fig. 11. Variation of $\mathrm{I}_{\mathrm{fd}}(26 \mathrm{~m} / \mathrm{c}$ system $)$

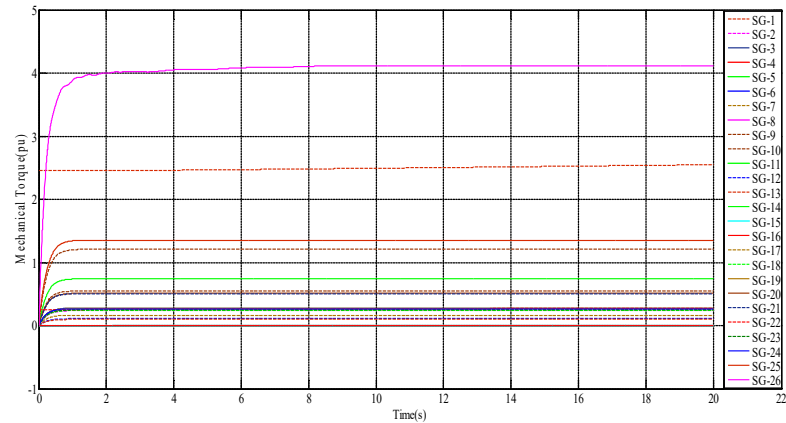

Fig. 12. Variation of Turbine output ( $26 \mathrm{~m} / \mathrm{c}$ system)

Case-2: Perturbation of $\mathrm{V}_{\text {ref }}$ for generator-1

For this simulation, in program execution of small signal (small_sig.m), network disturbances is set to zero. Then the perturbation of $\mathrm{V}_{\text {ref }}$ is set as one. The generator number whose $V_{\text {ref }}$ needs to be perturbed is given as 1 i.e. machine 1. The variation of the rotor angle, slip, field current, and turbine output obtained are taken up for analysis as shown in Fig. 13 through Fig. 16.

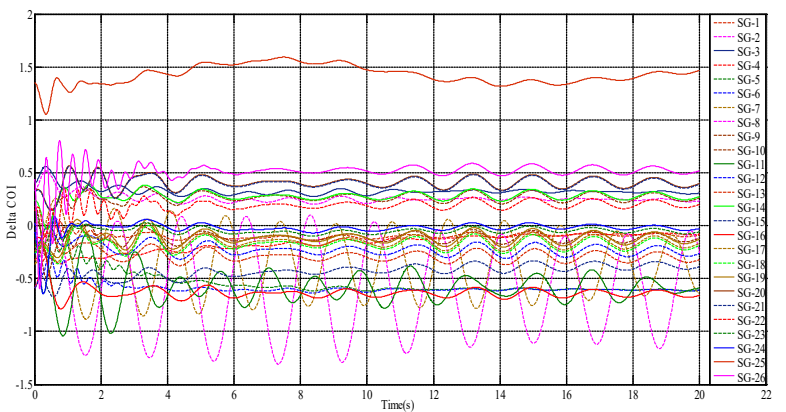

Fig. 13. Variation of rotor angles with respect to COI reference $(26 \mathrm{~m} / \mathrm{c}$ system) 
JAREE-Journal on Advance Research in Electrical Engineering Volume4, Number 1, April 2020

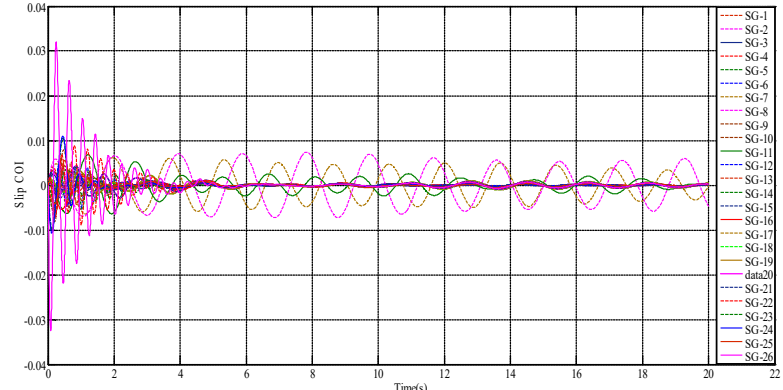

Fig. 14. Variation of slip with respect to COI reference $(26 \mathrm{~m} / \mathrm{c}$ system $)$

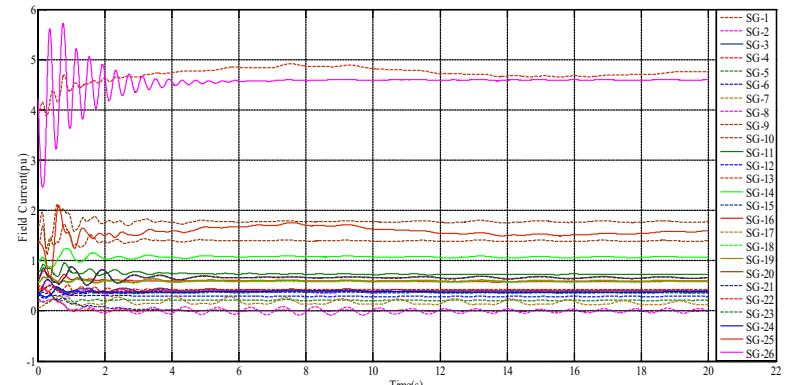

Fig. 15. Variation of $\mathrm{I}_{\mathrm{fd}}(26 \mathrm{~m} / \mathrm{c}$ system)

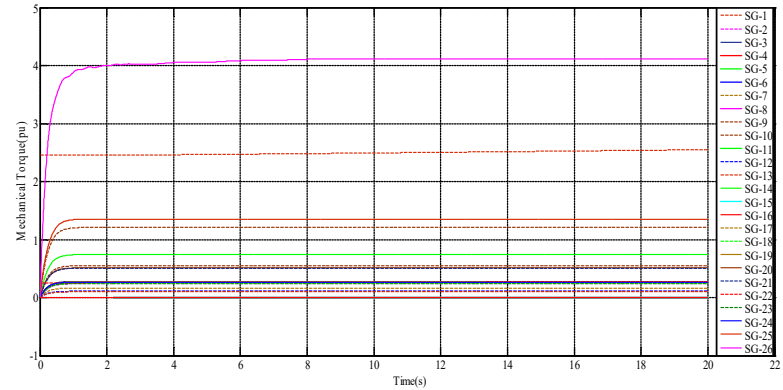

Fig. 16. Variation of Turbine output $(26 \mathrm{~m} / \mathrm{c}$ system $)$

Case-3: Ramping of $\mathrm{T}_{\mathrm{m}}$ for generator-1

For this simulation, in program execution of small signal (small_sig.m), network disturbances and perturbation of $\mathrm{V}_{\text {ref }}$ are set to zero. Then the ramping of $T_{m}$ is set as one. The generator number whose $T_{m}$ needs to be ramped-up/down is given as 1 i.e. machine 1 . The Turbine-governor on the chosen generator is disabled using TURB selector in the program. The simulation results for this case are shown in Fig. 17 through Fig. 20.

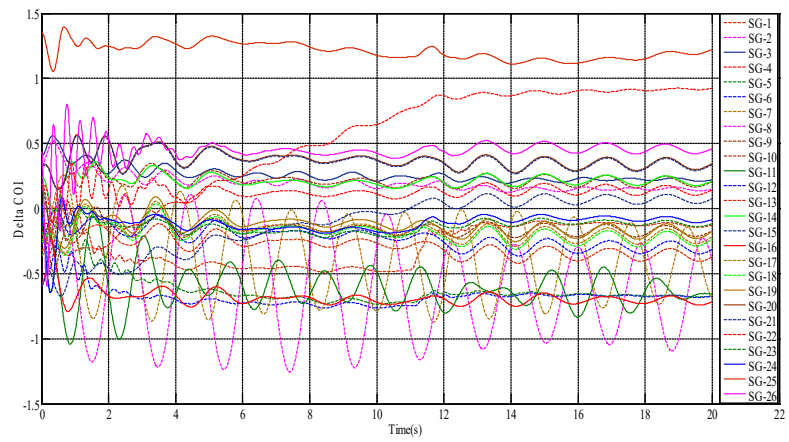

Fig. 17. Variation of rotor angles with respect to COI reference $(26 \mathrm{~m} / \mathrm{c}$ system)

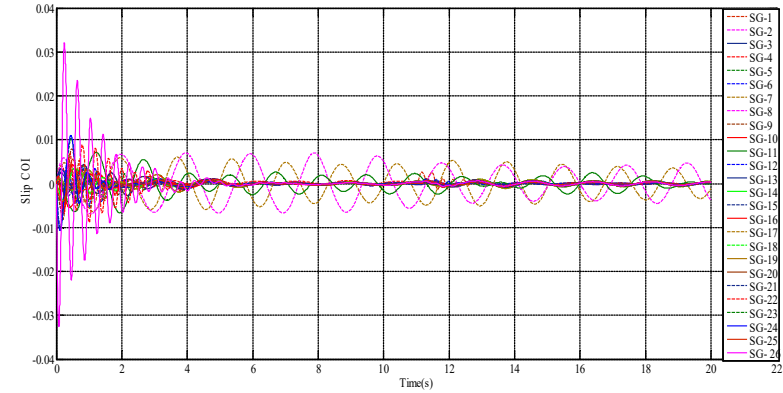

Fig. 18. Variation of slip with respect to COI reference $(26 \mathrm{~m} / \mathrm{c}$ system)

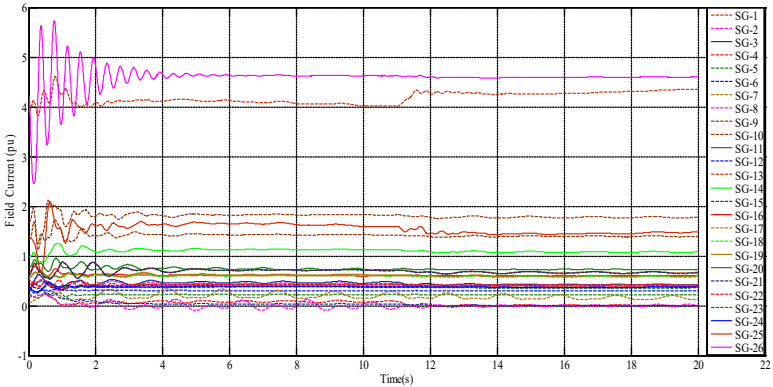

Fig. 19. Variation of $\mathrm{I}_{\mathrm{fd}}(26 \mathrm{~m} / \mathrm{c}$ system)

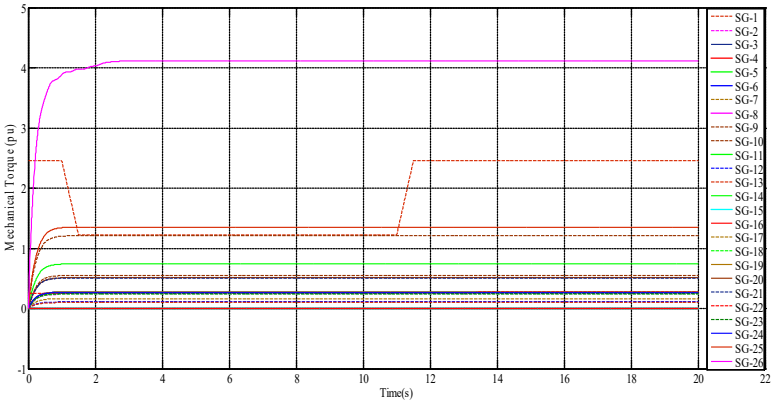

Fig. 20. Variation of Turbine output ( $26 \mathrm{~m} / \mathrm{c}$ system)

\section{Case-4: Network disturbances}

For this simulation, in program execution of small signal (small_sig.m), network disturbance is set as one. In this case, a three phase fault is applied at bus 46 at time $t=5 \mathrm{~s}$ and is cleared by tripping the line 24 . For a fault clearing time of $0.1 \mathrm{~s}$, the variation of the rotor angle, slip, field current, and turbine output are shown in Fig. 21 through Fig. 24.

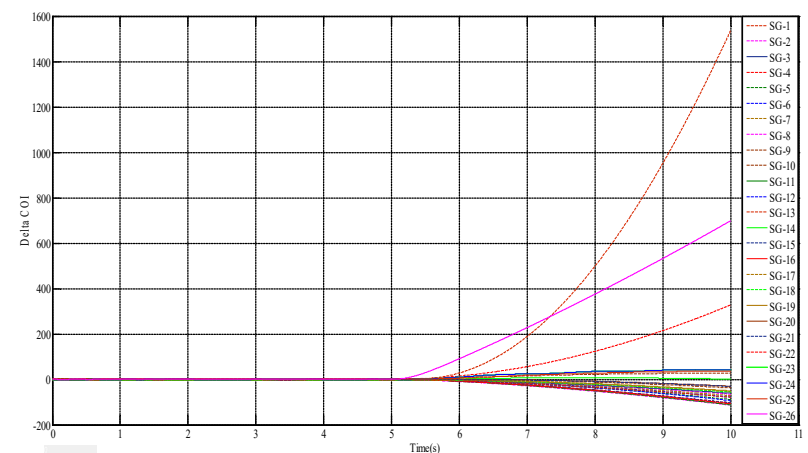

Fig. 21. Variation of rotor angles with respect to COI reference $(26 \mathrm{~m} / \mathrm{c}$ system) 
JAREE-Journal on Advance Research in Electrical Engineering Volume4, Number 1, April 2020

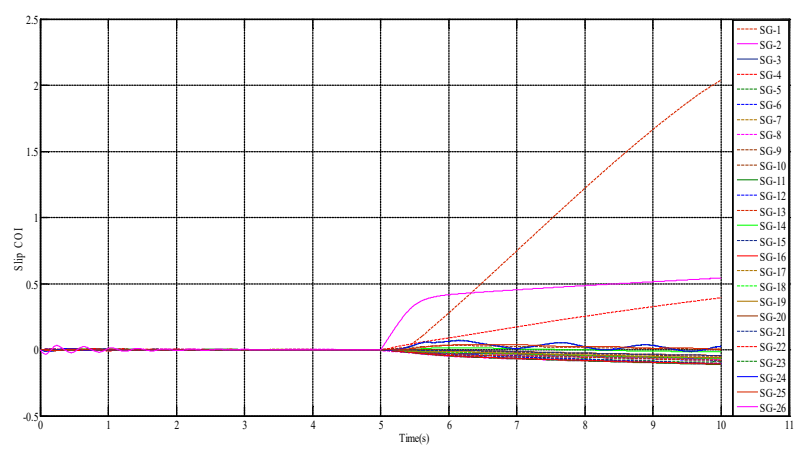

Fig. 22. Variation of slip with respect to COI reference $(26 \mathrm{~m} / \mathrm{c}$ system)

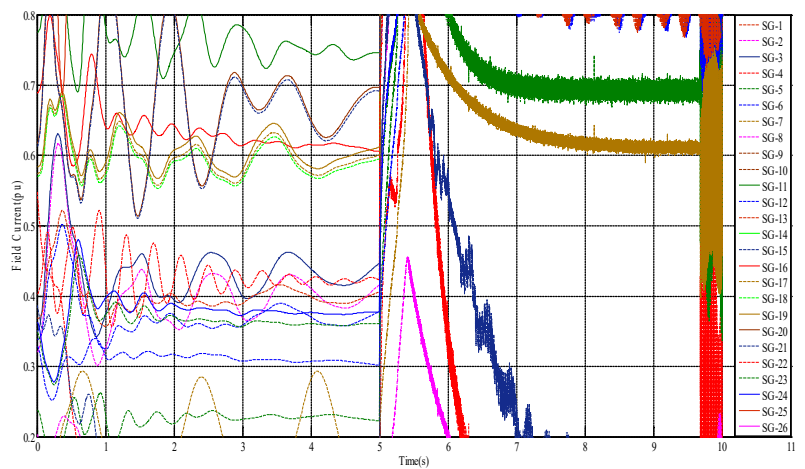

Fig. 23. Variation of $\mathrm{I}_{\mathrm{fd}}(26 \mathrm{~m} / \mathrm{c}$ system $)$

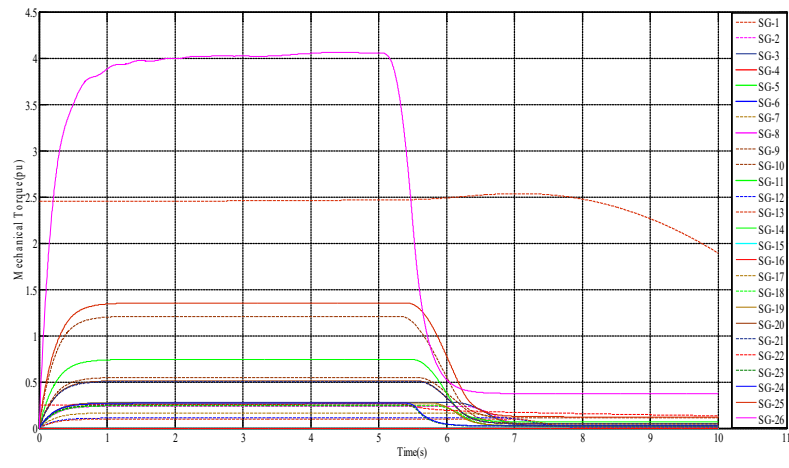

Fig. 24. Variation of Turbine output ( $26 \mathrm{~m} / \mathrm{c}$ system)

According to the simulation results, delta COI outputs of all machines are under steady condition for without disturbance case and $V_{\text {ref }}$ disturbance case. With $T_{m}$ disturbance, delta COI output of machine 4 is significantly increased from 0.3 to $0.9 \mathrm{pu}$. Under network disturbance condition, delta COI outputs of all machines are diverged showing the unstable conditions of the machines.

Slip COI outputs of all machines are unstable until $2 \mathrm{~s}$ and then stable for without disturbance case and with disturbance $\left(\mathrm{V}_{\text {ref }}, \mathrm{T}_{\mathrm{m}}\right)$ case. Under steady state condition, the slip COI variations for all machines are within $\pm 0.01 \%$ and thus the system is stable. Under network disturbance condition, slip COI outputs of all machines are continuously increasing and the steady operation condition is not occurred. Among them slip COI values of machine 1, 22 and 26 are very large compared to other machines.

Field current outputs of all other machines except for machine 1 are under steady condition for without disturbance case and $V_{\text {ref }}$ disturbance case. With $T_{m}$ disturbance, field current output of machine 1 is significantly increased from 4 to $4.4 \mathrm{pu}$ at 11 second. Similarly, the field current of machine 16 is slightly reduced at this instant. Under network disturbance condition, field current outputs of most of machines are in phase. After 9 seconds, all machines are in oscillations and unstable.

Turbine outputs of all machines are under steady condition for without disturbance case and $\mathrm{V}_{\text {ref }}$ disturbance case. With $\mathrm{T}_{\mathrm{m}}$ disturbance, turbine outputs of all other machines are under steady condition but machine 1 is dropped from 2.5 to $1.2 \mathrm{pu}$ at 1 second and maintain at this value until 11 seconds. After that turbine output of machine 1 rises again to $2.5 \mathrm{pu}$ and maintain at this value. Under network disturbance condition, turbine outputs of all other machines are significantly dropped within fault instant but machine 1 decrease at 8 seconds. Therefore, the system is unstable.

\section{CONCLUSIONS}

In this paper a multi-machine small-signal stability analysis programme has been developed using time- domain simulation. The programmes have been tested employing 58-bus, 26-machine power system of Yangon Distribution Network. The detail study is carried out for delta COI, slip COI, field current and mechanical torque. According to the simulation results, perturbation of $\mathrm{V}_{\text {ref }}$ shows only instability on the system. But ramping of Tm causes large disturbance on the system and unstable conditions can be observed. To maintain the small signal stability of the system, the application of power system stabilizer (PSS) is needed and should be done in further study.

\section{ACKNOWLEDGMENT}

The author thanks all of her teachers and friends who helped and encouraged her to complete this paper.

\section{REFERENCES}

[1] Nelson Martins, "Efficient Eigenvalue and Frequency Response Methods Applied to Power System Small-Signal Stability Studies", IEEE Transactions on Power Systems, Vol-1, No.1, February, 1986.

[2] P. Kundur, "Power System Stability and Control", McGraw-Hill Inc. New York, 1994.

[3] Peter W. Sauer and M.A. Pai, "Power System Dynamics and Stability", Prentice Hall, Inc. 1998.

[4] Hadi Saadat, "Power System Analysis", McGraw-Hill Inc. Singapore, 1999.

[5] K.R. Padiyar, "Power System Dynamics - Stability and Control", BS Publications, Hyderabad, India, 2008.

[6] K.N.Shubhanga and Y.Anantholla, "Manual for A Multi-machine Small Signal Stability Programme", NITK, Surathkal, 2009 [online].

[7] Pradeep and K.N.Shubhanga, "Manual for A Multi-machine Transient Stability Programme", NITK, Surathkal, 2009 [online].

[8] Debasish Mondal, Abhijit Chakrabarti, Aparajita Sengupta, "Power System Small Signal Stability Analysis and Control”, 1st Ed., Elsevier Inc. London, UK, 2014.

[9] M.J. Gibbard, P. Pourbeik and D.J. Vowles, "Small-signal Stability, Control and Dynamic Performance of Power Systems", University of Adelaide Press, Adelaide, 2015.

[10] B.J.Shah, G.N.Pillai, Pramod agarwal, "Power Oscillation Damping in Multi-Machine Power System Using PSS Considering Various Load models", Nirma University International Conference on Engineering 2013, 28-30 November, 2017.

[11] Anandkumar G. Acharya, B. J. Shah, "Small Signal Stability Improvement of Multi Machine Power System Using Power System Stabilizer", (IJEET) Volume 9, Issue 2, March- April 2018.

[12] Vikas Singh, H. Girisha Navada and K. N. Shubhanga, "Large Power System Stability Analysis Using a FOSS-based tool: SciLab/Xcos", the National Power Systems Conference (NPSC), India, December, 2018. 